\title{
Tradución e normalización da lingua galega no Concello de Ferrol. Pequeno estudo sobre a situación do sector cultural institucional
}

\author{
CRISTINA RÍo LÓPEZ
}

Resumo: A situación histórico-social e sociolingüística do Concello de Ferrol, ligada ao seu desenvolvemento como vila militar, maniféstase no baixo número de galegofalantes. Neste artigo examínase o labor cultural do Concello no tocante á normalización lingüística con axuda da tradución. Preséntanse as áreas de acción, os últimos avances, algunhas carencias e a análise dun corpus textual de institucións culturais, que revela unha aceptable calidade lingüística mais tamén erros significativos. Suxírese unha mellora lingüística e un estudo do interese dos cidadáns polo emprego da lingua na cultura, e da tradución como apoio en situacións sociolingüísticas adversas para o galego.

Palabras clave: Concello de Ferrol, Administración, cultura, historia, sociolingüística, normalización lingüística, lingua galega, tradución.

\begin{abstract}
Developed as a military town, the sociohistorical and sociolinguistic situation of the city of Ferrol translates into a low number of Galician speakers. This paper examines the cultural work of the City Council on language normalisation with the help of translation. The fields of action, the latest achievements and some shortcomings are presented. The analysis of a text corpus from cultural institutions reveals acceptable language quality but also significant errors. Suggestions are made for linguistic improvement and for studying the citizens' interest in the use of language in culture, as well as the role of translation in helping reverse sociolinguistic situations adverse to Galician.
\end{abstract}

Keywords: Ferrol City Council, Administration, culture, history, sociolinguistics, language normalisation, Galician language, translation.

${ }^{1}$ A autora quere expresarlle o seu fondo agradecemento a dona Mercedes Cabajales Iglesias, concelleira de Cultura, Educación e Universidade do Concello de Ferrol, pola súa amable e desinteresada colaboración, sen a cal este traballo ficaría gravemente eivado. 


\section{EN BREVE: PRINCIPAIS TRAZOS HISTÓRICOS, SOCIAIS E SOCIO- LINGÜÍSTICOS DO CONCELLO DE FERROL}

Unha das características que converte a cidade de Ferrol nun caso urbano e sociolóxico particular é o seu desenvolvemento coma vila dependente do poder estatal e estratéxica nos sentidos administrativo, naval e militar. Logo do seu nacemento, Ferrol tivo unha longa infancia que non acabou de deixar atrás ata a Ilustración. Así,

[s]e desconocen las épocas de los primeros asentamientos portuarios, aunque hay identificados restos arqueológicos romanos. La primera mención histórica es de 1087, pero con una villa y puertos de características muy elementales hasta 1726 en que comienza su gran desarrollo. Así pues se deben considerar dos etapas principales: la época de la Ilustración (siglo XVIII y parte del XIX) que es realmente la fundación, y la de su evolución posterior hasta hoy. (Rodríguez-Villasante Prieto, 2005: 671.)

A partir dese tempo, e por iniciativa estatal, foi crecendo unha fundación real concibida como capital do Departamento Marítimo do Norte, pois sobre as opcións que tiña La Concha de Artedo «prevaleció la ría de El Ferrol por sus mejores condiciones de abrigo y posibilidades de defensa» (García Fernández, 1988: s. n.). No mesmo sentido se manifesta Rodríguez-Villasante Prieto (2005: 673), quen declara que a comarca

no tenía prácticamente ninguna infraestructura portuaria, pero se estimó su gran
valor geoestratégico, de entrada estrecha y muy abrigado de todos los tempo-
rales [...], siendo prácticamente una comarca dependiente de la Armada a lo
largo de toda su historia hasta el siglo Xx [...]. Los factores militares fueron los
más importantes y derivados de la decisión política, tanto en su defensa te-
rrestre como marítima. Así, sobre una ría con poca población, se creó toda la
infraestructura portuaria militar, primero en la villa de La Graña y luego su
traslado a la zona contigua el pequeño puerto de San Julián de Ferrol, donde se
estableció el Arsenal a partir de 1750. Simultáneamente se fueron disponiendo
las fortificaciones en su costa y frente de tierra para obtener la defensa. La evo-
lución de este factor durante la Ilustración fue realmente decisivo, ya que Fe-
rrol fue la principal base naval de España [...]. El factor económico principal
se basó en la demanda de la Base Naval, siendo la producción y servicios ci-
viles muy pequeños, prácticamente dependientes de las demandas de la po-
blación civil que servía indirectamente en los Arsenales. Los recursos finan-
cieros también fueron del estado, ya que esta ciudadportuaria- militar [sic]
dependía de las consignaciones de la Real Hacienda [...].

Este percorrido vital influíu grandemente na composición da poboación de Ferrol, moi estratificada, pouco flexible e determinada polos rangos militares, por debaixo dos cales se achaba a base social: obreiros dependentes da actividade do Arsenal. Os labores militares e navais foron, de feito, os que propiciaron o enorme crecemento da poboación (inmigrante) durante a segunda metade do século XVIII, 
pasando de una población de menos de 3000 habitantes a superar la cifra de 30.000 , siendo al final de esta centuria la ciudad con mayor población de Galicia. Con respecto a las cualidades de este recurso humano, debemos destacar la disponibilidad de todo tipo de personal militar y marino, frente a una escasa existencia de civiles. Ferrol fue realmente una población militar hasta bien entrado el siglo xix. (Rodríguez-Villasante Prieto, 2005: 673-674.)

Historicamente, o estamento militar foi remiso a empregar o galego, tendencia que se observa claramente no caso da ditadura franquista (co enxalzamento do español como única lingua do Estado, o continuísmo dos prexuízos e da diglosia [Monteagudo e Bouzada Fernández, 2002b: 45] e mesmo a prohibición de usar as outras linguas peninsulares, so pena de castigo), que persiste na actualidade (Consello da Cultura Galega, 2005: 45) e que foi e é obxecto de demandas de restauración e revitalización da lingua, con medidas específicas destinadas ao persoal militar (Álvarez, Fernández e Santamarina, 1996/2004b: 119; Monteagudo e Bouzada Fernández, 2002a: 107). Pódese establecer unha relación entre a composición e o devir da sociedade ferrolá, por unha banda, e o moi escaso número de galegofalantes iniciais, pola outra: o 15,9\% segundo un estudo publicado en 2005 polo Consello da Cultura Galega; en 2008, a porcentaxe de persoas que tiveran o castelán como lingua da súa infancia era do 59,07. Súmase a isto un emprego maioritario do castelán tendente mesmo ao monolingüismo (Álvarez, Fernández e Santamarina, 1996/2004a: 56, 140-141, 252-255, 490; Consello da Cultura Galega, 2005: 52, 57, 59, 96; Fraga, 2010) e en datas recentes (o 81,5\% da poboación ferrolá emprega sobre todo o castelán, de acordo cun estudo realizado polo Instituto Galego de Estatística para o período 20032008).

Ante estas circunstancias, non resulta sorprendente que o devandito estudo do IGE revele que a porcentaxe de galegofalantes é, en Ferrol, a menor das grandes cidades galegas.

\section{O VALOR DA CULTURA DUN POBO}

Polas características históricas, sociais e sociolingüísticas non xa simplemente do Concello de Ferrol, senón de toda Galicia, o eido cultural desempeñou sempre unha función vital como motor da recuperación do galego, da súa revitalización, a súa dignificación e a súa normalización. Non pretendemos aquí facer un percorrido polas vicisitudes que experimentou o país neste sentido, pois non é o propósito deste artigo e se trata dunha cuestión ben estudada; mais si paga a pena lembrar exemplos como os da aparición (desde o Rexurdimento ata os nosos días) de obras literarias, publicacións de análise da realidade e da actualidade sociocultural, editoriais dedicadas exclusivamente á publicación ou á tradución de obras en galego, o florecemento das diversas artes; a creación de institucións de investigación e divulgación, como institutos, consellos, museos, ateneos, sociedades de «amigos de» e outros centros culturais; a organización de exposicións; iniciativas para espallar a cultura galega no estranxeiro; análise crítica dos estereotipos e os prexuízos sobre o galego; a relación da cultura co pa- 
trimonio, a ciencia, a tecnoloxía e outros eidos (se é que en algo se diferencia deles; véxase, por exemplo, o ciclo de conferencias que neste respecto organizou o Consello da Cultura Galega ao longo do 2007 co título Cultura Conciencia), entre outros factores.

Desde a mencionada época do Rexurdimento (século XIX), a recuperación e a dignificación do país e dos seus elementos característicos foron asociadas inextricablemente á recuperación e á dignificación do idioma galego. Isto púidose facer ben empregando o castelán como lingua vehicular (como adoitou suceder nos primeiros tempos), ben recorrendo á lingua propia, que vén sendo a práctica habitual e comprometida sobre todo desde o século XIX e, en especial, na súa segunda metade. Dado que neste traballo nos imos fixar no labor e nas actitudes dun determinado sector institucional, sempre será importante ter en conta, como pano de fondo, as perspectivas adoptadas polo Goberno (nomeadamente o da Xunta de Galicia a partir da época autonómica) con respecto á lingua galega. Con maior ou menor éxito e grao de compromiso, apréciase que os sucesivos Gobernos pretenderon pór en marcha políticas de defensa do galego que adoitaron ter o seu reflexo nas Administracións de niveis inferiores. Está por ver, con todo, o impacto que terá na lingua do país a xestión do que, na época de redacción deste artigo, era o último Goberno da Xunta, saído das eleccións autonómicas de marzo do 2009.

\section{A FUNCIÓN COADXUVANTE DA TRADUCIÓN}

Foi tamén polas mesmas datas do século XIX cando se lle empezou a conceder valor á tradución por motivos ligados aos nacentes nacionalismos europeos (Castro Vázquez, 2010: XXIII, 476, 479) e, no caso galego, ao movemento galeguista nas súas diversas vertentes. É ben sabido que a tradución literaria desempeña tradicionalmente unha importante función na (re)creación dun polisistema minoritario ou minorizado (véxanse especialmente os postulados de Even-Zohar, 1990a-h), e así é aínda no caso galego. Resume Hurtado:

La traducción, al formar parte de la cultura receptora, participa en la conformación del polisistema. Según Even-Zohar, la traducción tiene una función primaria (crear nuevos géneros y estilos) y otra secundaria (reafirmar géneros y estilos existentes). La función primaria se da con literaturas jóvenes que tienen sistemas literarios débiles y donde la traducción ocupa un lugar prominente. En el caso de literaturas de fuerte tradición, la traducción ocupa un lugar más marginal y sólo en épocas de crisis traducir puede convertirse en una actividad primaria. De todos modos, las circunstancias socioculturales de cada caso concreto marcarán siempre el papel de la traducción en cada polisistema así como la influencia del original sobre la traducción y la influencia de la traducción en la creación de textos originales. (Hurtado, 2001: 563.)

Das «subfuncións» que comprenden esas funcións primaria e secundaria poden ofrecerse múltiples exemplos: 


\section{- A tradución directa}

- pon o polisistema galego en contacto con outros, permitindo que entren no polisistema de chegada influencias de polisistemas alleos;

- contribúe a encher baleiros, como o causado polo baixo número de obras clásicas traducidas ao galego (e que moitas veces, sobre todo en épocas recentes e por iniciativa de editoriais de nova creación comprometidas coa cultura galega, están a ser traducidas por primeira vez á lingua do país; véxanse datos similares en Castro Vázquez, 2010: 479-481);

- fai posible coñecer a produción e o funcionamento de polisistemas foráneos (Castro Vázquez, 2010: 483);

- permite competir co polisistema que, en Galicia, é o dominante (o español) (Castro Vázquez, 2010: 478-479, 481);

$\circ$ etc.

\section{- A tradución inversa}

- achega Galicia e o galego ao resto do mundo;

- permite dar a coñecer autores galegos;

$\circ$ etc.

Mais un polisistema desenvolvido non pode basearse maiormente na literatura e na súa tradución, eiva que se lle ten aposto ao galego e que se está a solucionar grazas ao auxe da produción propia (en diversos ámbitos do coñecemento) e da tradución de obras de diversos formatos e non unicamente literarias. No eido que nos ocupa, o da cultura, podemos sinalar elementos tales como documentos e publicacións relacionados coas TIC, produción audiovisual, información relacionada con exposicións e outros actos de divulgación cultural, etc.

\section{A FUNCIÓN COADXUVANTE DOS CONCELLOS}

Ao seren o contorno inmediato do cidadán, o lugar onde este realiza as súas actividades vitais máis comúns, os concellos teñen algo —ou moito-que dicir para contribuíren á vida cultural dos veciños e mesmo dos visitantes.

Esa vida cultural dunha cidade non é un mero accesorio. Unha cultura local plena e florecente constitúe un factor de benestar cidadán, ofrece alternativas de lecer, aumenta os coñecementos dos habitantes mediante a divulgación de información local ou allea e, no ámbito do concello en si, serve para recuperar o patrimonio, descubrir - ou redescubrir-o lugar mesmo onde un vive, valorar o propio e, ao entrar en contacto con experiencias foráneas, avaliar criticamente o microuniverso local. Estes beneficios poden xurdir de iniciativas privadas ou populares (asociacións de veciños, asociacións culturais, fundacións, ateneos, etc.) ou da Administración, quer a local, quer as dun nivel superior. É ese estrato administrativo local o que vai ser obxecto da nosa análise. 
O ámbito cultural local é un eido máis onde pode actuar a normalización lingüística, pois os concellos teñen na súa man a posibilidade de poren o seu gran de area para recuperar, dignificar e difundir a lingua galega en vista da situación de anormalidade sociolingüística que sofre Galicia desde os Séculos Escuros (XVI-XVIII). Dada a intención da actual Xunta de Galicia de derrogar a Lei 3/1983, do 15 de xuño, de normalización lingüística, non estamos en condicións de garantirmos que os esforzos que ata agora se fixeron - repetimos, con maior ou menor éxito e insistencia - a prol da lingua galega vaian continuar polos mesmos vieiros. Con todo, si paga a pena lembrar que en Galicia se teñen promulgado diversas medidas lexislativas destinadas ás administracións locais, entre as cales podemos mencionar as seguintes:

- Lei 5/1988, do 21 de xuño, do uso do galego como lingua oficial de Galicia polas entidades locais.

- Lei 7/1985, do 2 de abril, regulamentadora das bases do réxime local. Modificada pola Lei 11/1999, do 21 de abril de 1999.

- Real Decreto 1690/1986, do 11 de xullo, polo que se aproba o Regulamento de poboación e demarcación territorial das entidades locais. Modificado polo Real Decreto 2612/1996, do 20 de decembro.

- Real Decreto 2568/1986, do 28 de novembro, polo que se aproba o Regulamento da organización, o funcionamento e o réxime xurídico das entidades locais.

- Real Decreto 1732/1994, do 29 de xullo, polo que se regula a provisión de postos de traballo reservados a funcionarios da Administración local con habilitación de carácter nacional.

- Orde do 10 de agosto de 1994 pola que se ditan normas sobre concursos de provisión de postos reservados a funcionarios da Administración local con habilitación de carácter xeral.

- Orde do 8 de setembro de 1994 pola que se aproba o modelo de convocatoria conxunta e as bases comúns polas que se teñen que rexer os concursos ordinarios para provisión de postos de traballo reservados a funcionarios de Administración local con habilitación de carácter nacional.

- Orde do 3 de xuño de 1986 pola que se desenvolve o Real Decreto $382 / 1986$, do 10 de febreiro, polo que se crea, se organiza e se regulamenta o funcionamento do rexistro de entidades locais.

E aquí é onde a tradución, pola súa vez, pode botar un cabo; de feito, algunhas das disposicións antes citadas conteñen referencias a medidas en que está implicada a tradución. Por unha banda, ademais do que dispoña a lexislación, débese ter en conta o compromiso lingüístico e o comportamento do concello de que se trate; pola outra, no país conviven, con maior ou menor éxito, dúas linguas oficiais, de xeito que toda iniciativa cultural dispón polo menos de tres alternativas obvias: 1) empregar unicamente o galego como lingua vehicular; 2) 
usar o castelán para este mesmo fin; ou 3) recorrer a ambos os dous idiomas. Deste xeito, en textos bilingües ou plurilingües o galego será a lingua de partida ou a de chegada, situacións que poden dar lugar a diversos problemas en función do caso de que se trate e do funcionamento do sistema administrativo (compromiso do concello co emprego do galego, calidade do seu equipo de normalización lingüística ou dos servizos externos contratados para fins lingüísticos, competencias tradutoras):

1) Cando o galego é a lingua de partida,

a) a redacción pode ser correcta,

b) a redacción pode conter erros.

2) Cando o galego é a lingua de chegada,

a) a tradución pode ser correcta,

b) a tradución pode conter erros,

c) tanto o orixinal como a tradución poden conter erros.

Nestes puntos xerais basearemos o noso estudo práctico, cuxa xénese e metodoloxía se presentan a seguir.

\section{BREVE ANÁLISE DO CASO FERROLÁN: CONCEPCIÓN E DESENVOLVEMENTO DA IDEA}

Ata hai ben poucos anos, o Concello de Ferrol sufriu un alarmante esmorecemento da súa vida cultural. Ao peche das salas de cinema — das que só unha fica en activo, ofrecendo unha programación que se podería cualificar como, en xeral, alternativa-, a deterioración de espazos como o Parque Raíña Sofía e outros acontecementos que fixeron que a poboación adoitase trasladarse aos concellos veciños - e mesmo non tan veciños - na procura de iniciativas de lecer (como ocorreu trala apertura dun gran centro comercial en Narón, que serviu de foco de atracción para un público de todas as idades), sumouse o progresivo abandono do uso de instalacións culturais institucionais, por un motivo ou por outro. Así, o Teatro Jofre, un dos máis importantes centros da cultura ferrolá, permaneceu en obras por rehabilitación desde decembro do 2001 ata decembro do 2005; a Biblioteca Central pasou por unha situación similar debido ás obras das súas propias instalacións e ás da inmediata Praza de España, estas últimas aínda sen concluír; e o castelo de San Felipe vive nunha constante incerteza sobre seu futuro, mentres proseguen os debates e disputas entre Concello, Xunta e Goberno español. Velaquí tan só uns poucos exemplos que coidamos que lle deberían servir ao lector para ter unha idea do que durante anos foi a perigosa decadencia da cultura ferrolá.

Mais, felizmente, semella que esta situación virou en certa medida nos últimos tempos. O Jofre volve ser o escenario de obras teatrais, espectáculos de danza, recitais, etc.; a inauguración da sede da Fundación Caixa Galicia foi o punto 
de partida de, entre outros, exposicións de arte, conferencias e ciclos de cinema para adultos e nenos; e déuselle un novo pulo á Fundación Torrente Ballester, a cal, aínda que cun público aínda humilde en cantidade, constitúe unha plataforma de expresión para a arte contemporánea ferrolá e de fóra do Concello (véxanse estes e outros exemplos en Blanco [2010], Irazu [2010] e Taboada [2010]).

No momento de redacción deste artigo, o Concello de Ferrol contaba cunha Área de Cultura, Educación e Universidade coordinada pola concelleira Mercedes Carbajales Iglesias (PSOE), que asumiu o seu cargo logo das eleccións municipais do 27 de maio do 2007. Destas eleccións xurdiu un goberno de coalición entre o Partido Socialista e Esquerda Unida, cuxa ruptura se produciu en outubro do 2008 e tivo como resultado o goberno en minoría do PSOE.

De acordo co sitio web do Concello, <http://www.ferrol.es>, e coa información subministrada pola concelleira da Área, as institucións que dependen da Administración ferrolá ou que dalgún modo están relacionadas con ela son o Arquivo, a Biblioteca Central, a de Caranza e a do Inferniño, o Centro Cultural Carballo Calero, o Centro Cívico de Caranza, o Centro Torrente Ballester e o Teatro Jofre. Así mesmo, existen exposicións permanentes en Aquaciencia (Parque Municipal Raíña Sofía), no Ateneo Ferrolán (ao cal o Concello lle cedeu a xestión e as actividades que se desenvolven no edificio, que é propiedade da Administración ferrolá), na Aula de Ecoloxía Urbana, no castelo de San Felipe, no mencionado Centro Torrente Ballester, en Exponav (propiedade de Defensa), no Museo da Sociedade Galega de Historia Natural (situado nun edificio municipal, mais cuxa xestión lle corresponde á SGHN), no Museo Naval (tamén de Defensa) e no Xornalismus.

Con todo, nada disto significa que as circunstancias da cultura en Ferrol sexan inmellorables, como ten comprobado a autora deste artigo por si mesma e en conversas mantidas con outros ferroláns e habitantes da comarca. Abofé, esa foi a fonte da que manou a idea base do que aquí presentamos.

Partimos de varias premisas: 1) o interese desta autora pola cultura; 2) a nosa condición de cidadá ferrolá; 3 ) a nosa formación e actividade profesional como tradutora e intérprete; 4) a nosa constante procura de xeitos en que conxugar todos os aspectos anteriores na vida cotiá e aplicalos ao mundo; 5) a potencia en acto da tradución como arma cargada de pasado, de presente e de futuro para entender a cultura e as culturas, como esta autora ten experimentado por si mesma e como manifestan estudos tales que os de Katan (2004).

A partir da visita a diversas exposicións e da compilación de catálogos e folletos destas, observáronse erros nas versións galegas —e, por veces, tamén nas españolas- que nos levaron a pensar en cal sería o modo de actuación do Concello de Ferrol no eido da tradución para a Área da Cultura. Para resolvermos esta cuestión e termos unha base sólida sobre a que avaliar o comportamento do Concello e o resultado (os textos producidos), puxémonos en contacto coa concelleira responsable da Área e transmitímoslle unha pequena listaxe de preguntas. Das respostas se deriva que toda a documentación administrativa, tanto desta Área como da de todo o Concello, ha estar redactada en galego por ser 
esta a lingua oficial do Concello. Así mesmo, existe unha ordenanza de normalización lingüística, aprobada polo Pleno en 1997, que regula os usos da lingua galega no Concello nos ámbitos de funcionamento da Administración municipal (cargos públicos, rexistro, toponimia, etc.). Cóntase tamén cun acordo plenario que establece a obrigatoriedade de incluír en todos os contratos, convenios e demais relacións establecidas con terceiros o que, segundo Carbajales, é unha «cláusula lingüística», pola cal «todo o que se derive desa relación terá o galego como lingua vehicular» (Carbajales, 2010).

Finalmente, o Concello dispón dun Plan de Normalización Lingüística aprobado en 2003 e que está en liña co disposto polo Consello Municipal da Lingua, órgano de asesoramento en política lingüística do Concello.

Canto á autoría dos textos de información cultural, folletos, catálogos, etc., son diversas as persoas que se encargan da súa preparación; por veces trátase do asesor cultural e, habitualmente —en especial no caso das publicacións-, os textos sométense á supervisión do departamento municipal de Normalización Lingüística.

Ademais de lle propormos as devanditas preguntas á concelleira, examinamos unha pequena compilación de documentos tomados de diversos actos culturais ${ }^{2}$ celebrados no Centro Torrente Ballester co obxecto de comprobar, con exemplos reais, como se plasma a actuación do Concello nas actividades ás que o público ten acceso directo:

- Revista e folla de sala exposición I Love You. Do 8 de febreiro ao 29 de marzo do 2008. Textos de Susana Cendán. Versión trilingüe en galego, español e inglés.

- Folla da exposición 5 visións desde os 90. Do 25 de abril ao 20 de xuño do 2008. Texto de Antonio Garrido Moreno. Versión monolingüe en galego.

- Cartón da exposición do XX Premio Internacional de Gravado «Máximo Ramos». Do 1 ao 31 de agosto do 2008. Versión monolingüe en galego.

- Folleto da exposición Teleprompter. Novas camuflaxes do pictórico. Do 29 de maio ao 22 de agosto do 2009. Textos de Miguel Cerceda, Ángel Cerviño, Chelo Matesanz, Álvaro Negro, Carme Nogueira, Luz Paz Agras, Anjo Rabunhal, Rafael Schacter e Anxos Sumai. Versión monolingüe en galego.

- Folla de sala da exposición Manuel Patinha. 20 anos de escultura. Do 16 de outubro ao 31 de decembro do 2009. Versión bilingüe en galego e español.

- Folla da videoproxección Carmencita. Do 28 de outubro ao 31 de decembro do 2009. Versión bilingüe en galego e español.

2 As datas dos actos son as que se mencionan nos documentos consultados; non se tiveron en conta aquí as ampliacións dos prazos de exhibición que experimentaron algúns deses actos. 
- Folla de sala da exposición Máximo pracer. Do 29 de outubro ao 31 de decembro do 2009. Versión bilingüe en galego e español.

- Folla do vídeo do mes Do Verbo Acumular / Del Verbo Acumular. 2010. Versión bilingüe en galego e español.

- Folla de sala da exposición Animalario. Do 22 de xaneiro ao 31 de marzo do 2010. Versión bilingüe en galego e español.

- Dúas follas de sala da exposición A Ousadía do Bufón. Pequenas Historias de Arte e Política. Do 22 de xaneiro ao 31 de marzo do 2010. Versión bilingüe en galego e español.

- Folla de sala da exposición Oriental References. Do 22 de xaneiro ao 31 de marzo do 2010. Versión bilingüe en galego e español.

- Folla de sala da videoproxección Ocaso. Centro Torrente Ballester, do 24 de abril ao 4 de xullo do 2010. Versión bilingüie en galego e español.

- Folla de sala da exposición ... Seguro? Centro Torrente Ballester, do 24 de abril ao 4 de xullo do 2010. Versión bilingüe en galego e español.

Durante a análise lingüística destes textos apreciouse que a redacción se move entre niveis de calidade que poderiamos considerar desde aceptables ata notables. Con todo, observáronse tamén deficiencias - algunhas delas, reiteradas- das que a seguir se presentan exemplos destacados en negra. Entre corchetes marcados tamén en negra figuran elementos necesarios dos que carece o texto orixinal. (Téñase en conta que algúns dos exemplos seguintes poderían incluírse en máis dunha sección.)

\section{- Erros gramaticais:}

- Erros de concordancia:

- O gravado, o mesmo que outros medios como o debuxo, foron situados de forma inxusta nun lugar secundario [...].

- [...] todo, desde os nosos libros e películas favoritas [...].

- Ausencia do obrigatorio pronome de obxecto indirecto:

- A escena actual [...] outorgou[lles] ás artes gráficas unha riqueza realmente envexable.

- [...] para que os poderosos se poñan de acordo para [lle] asegurar [ou asegurarlle] ao noso planeta un futuro verde e saudable e tamén de [lles] render [ou renderlles] unha homenaxe a todas as criaturas que tiveron un protagonismo secundario na historia da arte.

- [...] e iso, literalmente, proporciona [proporciónalle] cor á nosa perspectiva.

- Posición do pronome:

- [...] só a desmemoria pódeo evitar. 
- O ocaso dun día tormentoso o é tamén dunha certa concepción do humano.

- Expón con regularidade nos centros de arte máis prestixiosos e a súa obra se atopa depositada, entre outras, nas coleccións do Museo Nacional Centro de Arte Reina Sofía [...].

- O premio foi o deseño dunha casa para Josephine que, aínda que non chegou a realizarse, converteuse nunha das creacións más brillantes de Loos [...].

- [...] un debilitamento da posición do suxeito que agora, en nome dunha interacción efectiva, vese obrigado a reducir drasticamente o seu tempo de reacción.

- [...] contrólase a través dun pedal situado nos pés do propio lector que ao pisar faino avanzar ou o detén [...].

- Uso erróneo do pronome reflexivo:

- É como se as cousas se tivesen tragado o seu espello [...].

- Contraccións erróneas:

- Partindo dunha calculada escenografía, Do Verbo Acumular, é algo máis cun aceno aos traballos de Richard Serra [...].

- Mestura de réximes preposicionais:

- [...] dous novos creadores dos que podería estar falándolles horas, da súa incrible cultura visual, musical, cinematográfica ou do seu fantástico mundo interior no que, se te deixan entrar, xa non quererás saír.

- Uso erróneo das conxuncións:

- É como se as cousas se tivesen tragado o seu espello [...].

- Citas textuais en primeira persoa introducidas con «que» nun discurso en terceira persoa, combinando equivocadamente o estilo directo e o indirecto. (Mesmo erro na versión castelá.)

- Confusión de oracións explicativas e especificativas:

- De repente, alguén chamou á porta. Era unha das encargadas do servizo[,] que pedía permiso para entrar e recoller unhas bandexas.

- [...] dous novos creadores dos que podería estar falándolles horas, da súa incrible cultura visual, musical, cinematográfica ou do seu fantástico mundo interior[,] no que, se te deixan entrar, xa non quererás saír.

- Na súa habitación, intento demostrar unha humildade, que non podo sentir [...].

- Malia non constituír estritamente un erro gramatical, bótase en falta o uso do infinitivo conxugado cando a súa presenza é posible. 


\section{- Estilo:}

- Repeticións:

- No ano 1984, o Concello de Ferrol decide crear un concurso de creación plástica.

- Ausencia de comas:

- Con esta intelixente decisión conséguese unha resposta certamente sorprendente, o número e a calidade das obras presentadas[,] así como a súa procedencia, cunha porcentaxe elevada de artistas internacionais, sitúan de maneira inmediata o certame nun lugar destacado dentro do calendario cultural do noso país.

- [...] eficaz anestésico que alimenta diariamente a imaxinación de millóns de espectadores de todo o mundo, pero que[,] trala súa aparente inocencia, oculta o poder para dictar unha serie de convencións [...]. [Mesmo erro na versión española.]

- Uso de comas no canto de, por exemplo, os dous puntos ou o punto e coma:

- Os cambios, como é lóxico, non afectan só aos aspectos técnicos da estampación, as distintas correntes e tendencias artísticas tiveron reflexo no noso certame [...].

- Non é doado manter un certame como o Máximo Ramos ao longo de tantos anos, sirva esta exposición como homenaxe a todas aquelas persoas que o fixeron posible e como testemuño de compromiso co seu futuro.

\section{- Faltas ortográficas e ortotipográficas:}

- Separación do suxeito do predicado con coma:

- A vía de expansión dos campos da escultura nos que a arquitectura, o espazo circundante, o tempo, a paisaxe, o compromiso co medio natural ou social, e o espectador, pasan a formar parte esencial dos proxectos creativos [...].

- Partindo dunha calculada escenografía, Do Verbo Acumular, é algo máis cun aceno aos traballos de Richard Serra [...]. [Mesmo erro na versión española.]

- Resulta difícil desentrañar o enigma, pois este creador establecido en Nova York, é reticente a dar pistas sobre a súa vida [...].

- Esta artista especial que mantivo o alcume que lle deron de nena en alusión ao personaxe de Pippi Calzaslargas, combinou coma ninguén a cultura pop coa historia da arte. [Mesmo erro na versión española.]

- A chamada estetización xeral da existencia, conduce, como era previsible, á crise da categoría estético-artística [...]. 
- Comas innecesarias ante conxuncións, que por veces levan á separación do suxeito do predicado:

- [...] diversas poéticas pos-vangardistas tales como o minimalismo, povera, land art, ou neo-expresionismo [...].

- A avalancha de microblogues, e a metástase sen fin dos vídeos confesionais, son os indicadores máis evidentes dun cambio de escenario $[\ldots]$.

- [...] un sistema xerarquizado que inclúe calquera clase de imaxe xerada, almacenada, ou posta en circulación coas ferramentas tecnolóxicas que a industria proporciona [...].

- Ausencia de comas necesarias:

- A Sala de Proxectos presenta o traballo de Agar Fernández Bautista (Porriño. Pontevedra, 1980)[,] unha deseñadora nova cunha sólida formación [...]. [Mesmo erro na versión española.]

- Que aconteceu?[,] que está a acontecer? [Mesmo erro na versión española.]

- [...] ao seu lado amontóanse os símbolos do G8[,] pacientes xeradores do contexto.

- Unha mostra gráfica e pictórica encabezada pola impoñente representación do dogo de Eduardo de la Vega (A Coruña 1861 - Ferrol 1943)[,] unha pintura chea de contidos subliminares. [Mesmo erro na versión española.]

- Referencias consistentes? [,] pensou Ana. [Mesmo erro na versión española.]

- Marina Núñez (Palencia, 1966)[,] unha das artistas con maior proxección do noso país [...]. [Mesmo erro na versión española.]

- Coñezo o de París, Milán, Edimburgo, Roma...[,] de todos eles teño fotografías marabillosas.

- Uso errado das maiúsculas e as minúsculas:

- [...] entre os que se atopan os pintores Ricardo Segura Torrella e Jorge LLorca [...].

- [...] unha revista en formato dvd que nos fascinou a moitos. [Mesmo erro na versión española.]

- Acentuación:

- As imaxes de Klimt vestindo austeras túnicas, longas ata os pes [...].

- O Video do Mes inicia nova tempada [...]. [Mesmo erro na versión española.] 
- Uso errado das comiñas:

- [...] e a frase máis romántica que Ana lle dedicara continúa gravada na memoria do seu teléfono móbil: "es o +". [Mesmo erro na versión española.]

- Levantou a vista e exclamou: "que bonito". [Mesmo erro na versión española.]

- Uso simultáneo de comiñas e itálica para marcar citas textuais.

- Ausencia de marcas tipográficas que distingan os nomes dos eventos ou das obras (comiñas ou itálicas):

- A exposición Manuel Patinha. 20 anos de escultura resume dúas décadas de traballo do artista de orixe portuguesa Manuel Patinha [...].

- Carmencita é un proxecto concibido especialmente para a Sala de Proxectos do CTB [...].

- Naquel episodio mítico de Mulleres Desesperadas, Gabrielle era, metaforicamente, o Ferrari ao que Zac trata de roubarlle un bico.

- Sabemos que é o director creativo de Fly, unha das novidades editoriais máis frescas dos últimos tempos. Unha revista en formato $d v d$ que nos fascinou a moitos. [Mesmo erro na versión española.]

- Uso do trazo no canto da raia para representar diálogos (e separando o trazo, erradamente, da palabra que vai a seguir):

- - Están tomando fotos de xente tomando fotos [...].

- Mestura de guións para incluír incisos; adición errónea de guións de peche ao final de oración:

- Isto non significa a renuncia a experimentar con outros materiais - como o granito, resinas e outros materiais- ou contextos creativos. [Mesmo erro na versión española.]

- Unha selección que permite corroborar a especificidade dun excelente debuxante, un consumado gravador - sobre todo á augaforte- e un artista único [...]. [Mesmo erro na versión española.]

- Participou en numerosas exposicións individuais e colectivas Photogalicia, Instituto Cervantes de Milán, Viena e Roma, Fundación Caixa Galicia, ARTIUM..... [Erro similar na versión española.]

- Separación do dígrafo nh a final de liña: Nun-has obras asomará o político como configurador do visual [...].

- Indicación dos minutos e os segundos de duración dun vídeo mediante os símbolos dos minutos e os segundos dos ángulos planos (e sen espazo en branco entre ambas as magnitudes): 3' 13", 5'41".

- Espazos en branco sobrantes: ¿ Desexábao? Demasiado tarde. 
- Ausencia de espazos en branco necesarios (por veces esta ausencia dáse na versión española mais non na galega nin na inglesa):

- ... a nova situación empurrou á pintura fóra dos espazos (físicos e mentais) que outrora dominaba [...].

- ...viuse obrigada a concertar turbios acordos cos seus veciños dixitais $[\ldots]$.

- Topónimos: Tokio.

- Miscelánea:

- [...] para afondar naqueles temas sobre os que se asinta o seu particular universo creativo [...].

- [...] pero a ocasión ben merece a licencia. [O texto en cuestión está escrito usando a versión máis actualizada da normativa da Real Academia Galega.]

- [...] oculta o poder para dictar unha serie de convencións [...]. [Véxase o comentario anterior.]

$\circ$...Seguro?

\section{- Inconsistencias:}

- Presenza e ausencia do signo de apertura de interrogación en textos pertencentes á mesma época e redactados coa mesma normativa:

- Referencias consistentes? pensou Ana.

○ ¿Un gato? Non.

\section{- Incoherencias:}

- María, camareira, brasileña, 18 anos, 1,77 cm. [Mesmo erro na versión española, mais non na inglesa.]

\section{- Léxico e semántica:}

- Unha traxectoria na que xogou un papel decisivo o aceiro [...].

- É estraño o que o desexo fará facer a xente tonta

- Alguén nos dixo que a vista dende o alto do cemiterio era a máis bonita do pobo.

- María, camareira, brasileña [...].

- O anuncio compleméntase cunha páxina web -www.hoynoessanvalentin.com - que aglutina todo o necesario para celebrar o amor: horóscopo, test do amor, poemas, teletenda, foro e por suposto un servizo de cancións [...]. [Mesmo erro na versión española, mais non na inglesa, a cal se refire correctamente a un website ou sitio web, distinto dunha páxina web. Nótese o frecuente que resulta o uso erróneo de páxina por sitio tanto en galego como en español.] 
- Na súa habitación, intento demostrar unha humildade, que non pode sentir $[\ldots]$.

- Trátase agora, para que o que de verdade importa emerxa e adquira plena visibilidade, de investir o proceso de dislocación temporal [...].

- O triunfo do simulacro aséntase sobre esa confusión [...] entre experiencia e representación, trama e urdimbre da nosa desgraza.

\section{- Erros de tradución do inglés para o galego:}

- Strange what desire will make foolish people do > É estraño o que o desexo fará facer a xente tonta [Mesmo erro na versión española; neste caso, a forma will indica hábito ou afirmacións xerais. Nótese, ademais, o forzado da tradución.]

Poderíanse engadir outras categorías que, en sentido estrito, xa serían alleas á lingua galega e ao propósito deste traballo, como faltas de ortografía en palabras escritas noutras linguas. É interesante notar, así mesmo, que, malia algúns destes textos estaren escritos unicamente en galego na documentación analizada, presentan erros que suxiren un orixinal castelán ou un claro castelanismo (por exemplo, o uso do pronome reflexivo).

\section{CONCLUSIÓNS}

Da pequena investigación realizada despréndese que o Concello de Ferrol se preocupa hoxe en día por dinamizar a vida cultural da cidade; de feito, a Área de Cultura é unha das máis valoradas polos partidos municipais nas súas avaliacións da actuación do goberno (Pita Parada, 2010). Existen políticas lingüísticas locais que efectivamente se levan á práctica e unha das plasmacións desta actuación é a textual: na Área de Cultura, á cal lle dedicamos esta análise, prodúcense textos que, segundo as nosas observacións, se presentan sistematicamente en galego. Con moita frecuencia levan aparellada a súa versión en castelán, e mesmo - aínda que de raro en raro e probablemente en función da difusión que se lle pretenda dar ao escrito- en inglés.

O estudo non nos permitiu achar a autoría das traducións dos textos culturais: autotradúcense os redactores?, encoméndaselles tal tradución a outros servizos administrativos, ou talvez a provedores externos? Ignorámolo, mais o que si sabemos é que, como era de esperar, esta autoría non é uniforme (non lle corresponde a un único redactor a elaboración de todos os textos da Área) e que os textos se someten a revisión. Con todo, ao analizar un corpus tomado dunha das institucións xestionadas polo Concello de Ferrol, comprobouse que os documentos contiñan un número apreciable de erros lingüísticos de diversa clase, máis ou menos graves, doadamente corrixibles e probablemente debidos a diferentes motivos en función de cada caso. Estas deficiencias obsérvanse tanto nas versións galegas como nas castelás, cunha puntualización: os castelanismos das primeiras non teñen, en ningún dos casos analizados, o seu equivalente en galeguismos nas versións (orixinais ou traducidas?) españolas. Curiosamente, o 
nivel de calidade e o número e a clase de erros son moi similares en galego e en castelán, mais non no caso das traducións inglesas: cando estas existen, apréciase un maior coidado na redacción e, en xeral, unha maior calidade textual.

Isto lévanos a supor que, dalgún xeito, existe certa dependencia recíproca entre as versións galegas e as castelás; certo paralelismo ao que escapan os textos ingleses, non necesariamente suxeitos á percepción da calidade que poidan ter os autores dos textos galegos e españois e, sen dúbida, non necesariamente influídos pola situación de bilingüismo (non harmónico) do país. Así, nalgúns casos percíbese con claridade a influencia que exerce un orixinal castelán no texto galego, ou ben o imbricada que está a lingua española na mente do redactor, mesmo á hora de escribir en galego sen un orixinal castelán previo.

Non obstante, a calidade da redacción, vista en conxunto, é máis que aceptable e podería chegar a notable simplemente con someter os textos a unha revisión máis fonda. Así mesmo, cremos que é digna de louvanza a actitude do Concello de Ferrol no tocante ao uso do galego nas instalacións culturais que dependen da Administración local.

Un aspecto que nos preocupa neste mesmo ámbito local radica na escasa difusión que poden ter as diversas iniciativas entre os cidadáns; lémbrese o que se apuntou ao comezo deste artigo con respecto á captación de visitantes ferroláns por parte doutros concellos de Ferrolterra e da bisbarra coruñesa, que moitas veces ofrecen alternativas de lecer especialmente concibidas para nenos, mozos e familias (e que a estes lles resultan aínda máis atractivas por estaren incluídas, con frecuencia, en centros comerciais).

Así mesmo, existe un outro factor que pagaría a pena estudar nun contexto máis amplo que o deste artigo: ata que punto os cidadáns consideran relevante o uso do galego nas instalacións que visitan.

Non abonda con lles formularmos preguntas illadas e informais aos nosos coñecidos, como se fixo durante a preparación deste artigo por unha mera cuestión de curiosidade. O conveniente sería realizar enquisas que servisen para avaliar o grao de interese, de atención e de compromiso dos cidadáns e a súa opinión sobre aspectos como os seguintes:

- Que opinan do emprego do galego por parte da Administración local no eido cultural e, en xeral, na vida diaria do seu concello?

- Valoran que os textos que se lles presentan estean redactados apropiadamente e que, na fala, os discursos sexan correctos?

- De maneira xeral, valoran que se use ben a lingua en calquera ámbito?

- Teñen percibido algún erro lingüístico na oferta cultural difundida pola Administración local? E sobre todo, en caso afirmativo, concedéronlles algunha importancia a tales erros?

- Que experiencia teñen os cidadáns dos textos ou discursos monolingües (en galego ou en español) ou bilingües nestes dous idiomas? Oféndense ou moléstanse se só se emprega unha das linguas? 
— No caso dos textos bilingües, que versión tenden a ler? Paráronse algunha vez, por algún motivo, a comparalas ambas?

— É a lingua un aspecto considerado «menor» ou «non tan relevante» como outras cuestións que, na percepción dos cidadáns, sexan directamente prácticas e aplicables á súa vida?

Esperamos que este pequeno estudo poida servir de base para unha análise máis ampla e polo miúdo que dea conta de como concellos como o de Ferrol, de tamaño medio e historicamente afectados por circunstancias lingüísticas adversas, poden encarar estas adversidades e apoiarse na tradución (de calidade) para cumpriren a súa misión cultural: unha misión que debería ser, no fondo, facer máis agradable e plena a vida dos seus habitantes.

\section{FONTES}

Álvarez Blanco, R.; Fernández Rei, F.; Santamarina, A. (eds.) (1996/2004a): A Lingua Galega: historia e actualidade. Actas do I Congreso Internacional. Santiago de Compostela, 16-20 de setembro de 1996. Vol. I. [en liña]. Organizado polo Instituto da Lingua Galega. Santiago de Compostela: Consello da Cultura Galega / Instituto da Lingua Galega, <http://consellodacultura.org/mediateca/pubs.pdf/galego_historia.pdf/>. [Última consulta: 4 de maio do 2010.]

- (1996/2004b): A Lingua Galega: historia e actualidade. Actas do I Congreso Internacional. Santiago de Compostela, 16-20 de setembro de 1996. Vol. II [en liña]. Organizado polo Instituto da Lingua Galega. Santiago de Compostela: Consello da Cultura Galega / Instituto da Lingua Galega. <http://consellodacultura.org/mediateca/pubs.pdf/galego_historia_2.pdf/>. [Última consulta: 4 de maio do 2010.]

Blanco, P. (2010): «Los ámbitos culturales de Ferrol: sus espacios». La Voz de Galicia (ed. de Ferrol), 19 de xuño do 2010, p. L8.

CARBAJALEs Iglesias, M. (30 de xuño do 2010) [respostas a preguntas formuladas pola autora sobre diversos aspectos da Área de Cultura, Educación e Universidade do Concello de Ferrol] [en liña]. Mensaxe electrónica enviada á autora deste traballo.

CASTRO VÁzQUEZ, O. (2010): Tradución, xénero, nación: cara a unha teoría e práctica da tradución feminista. Tese de doutoramento inédita. Vigo: Departamento de Tradución e Lingüística, Universidade de Vigo.

MÉNDEZ, L. (coord.) (s. d.): Atlas Mundial Galego Online (versión provisional) [en liña]. Compañía de Radio Televisión de Galicia (CRTVG). Servizo de Normalización Linguística. Santiago de Compostela: Televisón de Galicia. <http://atlas.lucanus.es/>. [Última consulta: 3 de xullo do 2010.]

CONCELlo de Ferrol (2003): Plan de normalización lingüística. Ferrol: Concello de Ferrol.

— (2010) [en liña]. Ferrol: Concello de Ferrol. <http://www.ferrol.es>. [Última consulta: 3 de xullo do 2010.]

Consello da Cultura Galega [en liña]. Santiago de Compostela: Consello da Cultura Galega. $<$ http://consellodacultura.org $>$. [Última consulta: 26 de xuño do 2010.] 
—: Culturagalega.org [en liña]. Santiago de Compostela: Consello da Cultura Galega. $<$ http://www.culturagalega.org $>$. [Ultima consulta: 4 de xullo do 2010.]

—. Arquivo de Planificación e Normalización Lingüística (2002): Actas dos IV Encontros para a Normalización Lingüística. Santiago de Compostela, 9 e 10 de novembro do 2000. Santiago de Compostela: Consello da Cultura Galega.

—. Comisión Técnica de Lingua e Sociedade. Sección de Lingua (2005): A sociedade galega e o idioma: Evolución sociolingüística de Galicia (1992 - 2003) [en liña]. Santiago de Compostela: Consello da Cultura Galega. $<$ http://consellodacultura.org/mediateca/pubs.pdf/lingua_sociedade.pdf/>. [Última consulta: 4 de maio do 2010.]

- Loia: guía aberta á lingua galega [en liña]. «Historia». $<$ http://www.consellodacultura.org/arquivos/cdsg/loia/histor ia.php?idioma=1\&id=45> e ss. [Última consulta: 5 de maio do 2010.]

Even-Zohar, I. (1990a): «Interference in Dependent Literary Polysystems», Poetics Today, vol. 11, no. 1, pp. 79-83.

— (1990b): «Introduction», Poetics Today, vol. 11, no. 1, pp. 1-6.

— (1990c): «Laws of Literary Interference», Poetics Today, vol. 11, no. 1, pp. 53-72.

— (1990d): «Polysystem Theory», Poetics Today, vol. 11, no. 1, pp. 9-26.

— (1990e): «System, Dynamics, and Interference in Culture: A Synoptic View», Poetics Today, vol. 11, no. 1, pp. 85-94.

— (1990f): «The "Literary System"», Poetics Today, vol. 11, no. 1, pp. 27-44.

— (1990g): «The Position of Translated Literature within the Literary Polysystem», Poetics Today, vol. 11, no. 1, pp. 45-51.

— (1990h): «The Position of Translated Literature within the Literary Polysystem», Poetics Today, vol. 11, no. 1, pp. 45-51. [Trad. gallega: Gómez Clemente, X. M.; Noia, C.; Sola Bravo, M. (1996): «A posición da traducción literaria dentro do polisistema literario» (intr.: Camino Noia), Viceversa, núm. 2, pp. 57-65].

- (1990i): «Translation and Transfer», Poetics Today, vol. 11, no. 1, pp. 73-78.

Fraga, X. (2010): «O número de galegofalantes baixa, pero segue a manterse maioritario», La Voz de Galicia, 16 de abril do 2010.

Freixeiro Mato, X. R.; Gómez SÁnchez, A. (1998): Historia da Lingua Galega. Vigo: A Nosa Terra.

GARCÍA FERNÁNDEZ, J. L. (1988): Urbanismo español e hispanoamericano (1700-1808). [Copia mecanografada sen numerar.]

GonZÁlez ReI, B. (2004): Ortografía da lingua galega. A Coruña: Galinova.

Graña Martínez, V. (2001): Lexislación da lingua galega. Xunta de Galicia. Consellería de Educación e Ordenación Universitaria. Dirección Xeral de Política Lingüística.

Hermida, X. (2005): «Caixa Galicia convierte el antiguo Gobierno Militar de Ferrol en un gran centro cultural» [en liña]. El País, 30/04/2005. <http://www.elpais.com/articulo/cultura/Caixa/Galicia/convier te/antiguo/Gobierno/Militar/Ferrol/gran/centro/cultural/ elpepicul/20050430elpepicul_2/Tes/>. [Ultima consulta: 26 de xuño do 2010.] 
HuRTADo AlBIR, A. (dir.) ('1999): Enseñar a traducir. Madrid: Edelsa Grupo Didascalia.

Instituto Galego De Estatística (2010a): Enquisa de condicións de vida das familias. Coñecemento e uso do galego. <http://www.ige.eu/web/mostrar_actividade_estatistica.jsp?idioma $=$ gl\&codigo $=0206002001>$. [Última consulta: 4 de maio do 2010.]

—. «O 56,4\% da poboación fala maioritariamente en galego». 15 de abril do 2010 . $<$ http://www.ige.eu/estatico/pdfs/s5/notas_prensa/com_galego_2008_gl.pdf >. [Última consulta: 4 de maio do 2010.]

IRAZU, R. (2010): «Unas posibilidades inmensas». La Voz de Galicia (ed. de Ferrol), 19 de xuño do 2010, p. L8.

IR Indo Edicións (2008): Dicionario de galego [en liña]. Vigo: Ir Indo. $<$ http://www.digalego.com/>. [Última consulta: 3 de xullo do 2010.]

KaTAN, D. (2005): Translating Cultures. An Introduction for Translators, Interpreters and Mediators. Manchester: St. Jerome.

Loureiro, R. (2005): Jofre. O teatro que soñou unha cidade. A Coruña: La Voz de Galicia.

Martínez De Sousa, J. (2001): Maual de estilo de la lengua española. 2. ${ }^{a}$ ed., rev. y ampl. Gijón: Trea.

Monteagudo, H.; BouZada FernándeZ, X. (coords.) (2002a): O proceso de normalización do idioma galego (1980-2000). Volume I: «Política lingüística: análise e perspectivas» [en liña]. Santiago de Compostela: Consello da Cultura Galega. $<$ http://consellodacultura.org/mediateca/files/2009/09/normalizacion_vol_i.pdf >. [Última consulta: 4 de maio do 2010.]

- (2002b): O proceso de normalización do idioma galego (1980-2000). Volume II: «Educación» [en liña]. Santiago de Compostela: Consello da Cultura Galega. $<$ http://consellodacultura.org/mediateca/files/2009/09/norma_ii.pdf $>$. [Última consulta: 4 de maio do 2010.]

Pita PARAdA, R. (2010): «Tres años de controvertido gobierno», La Voz de Galicia (ed. de Ferrol), 20 de xuño do 2010. <http://www.lavozdegalicia.es/ferrol/ 2010/06/20/0003_8561357.htm>. [Última consulta: 3 de xullo do 2010.]

Real Academia Galega (1997): Diccionario da Real Academia Galega. A Coruña: Xerais / Vigo: Galaxia.

Rodríguez-Villasante Prieto, J. A. (2005): «Ficha de puertos: una propuesta a partir del ejemplo de Ferrol (época de la Ilustración)», en RodRíGUEZ-VILLASANTE PRIETO, J. A. (coord.) (2005): Encuentro Científico Internacional sobre Itinerarios Culturales. Actas del Comité Científico Internacional de Itinerarios Culturales (CIIC). Núm. 2. Encuentro organizado por el Comité Español del Consejo Internacional de Monumentos y Sitios (ICOMOS) en colaboración con el Comité Científico Internacional de Itinerarios Culturales. Ferrol (España), 1, 2 y 3 de octubre de 2004. Ferrol: Ayuntamiento de Ferrol - Concello de Ferrol, pp. 665-687.

TABOADA, R. (2010): «Ferrol, espacio escénico creativo». La Voz de Galicia (ed. de Ferrol), 19 de xuño do 2010, p. L8.

Thomson, A. J.; Martinet, A. V. ( $\left.{ }^{4} 1986\right)$ : A Practical English Grammar. Oxford: Oxford University Press. 
VV. AA. (2009): «Elecciones Gallegas 2009»[en liña]. La Voz de Galicia. $<$ http://www.lavozdegalicia.com/especiales2009/eleccionesgallegas/index.htm>. [Ültima consulta: 5 de maio do 2010.]

Xunta de Galicia. Secretaría Xeral de Política lingüística. Datos básicos da lingua galega [en liña]. <http://www.xunta.es/linguagalega/datos_basicos_da_lingua_galega $>$. [Última consulta: 3 de xullo do 2010.] 